REVISTA X, Curitiba, volume 13,n.1,p. 35-56, 2018.

\title{
A LÍNGUA QUE ACOLHE PODE SILENCIAR? REFLEXÕES SOBRE O CONCEITO DE "PORTUGUÊS COMO LÍNGUA DE ACOLHIMENTO"
}

\author{
Can the Language that Welcomes also Silence? Reflexions on the Concept of \\ "Portuguese as a Welcoming Language"
}

Renata Franck Mendonça de ANUNCIAÇÃO, IEL-UNICAMP ${ }^{1}$

\begin{abstract}
RESUMO: Considerando a relação intrínseca entre poder, língua(gem) e identidade, o objetivo deste artigo é focalizar o conceito língua de acolhimento (ANÇÃ, 2008; CABETE, 2010; GROSSO, 2010), discutindo quais políticas e práticas de ensino podem estar a ele vinculadas, levando em conta os posicionamentos teórico-ideológicos subjacentes. A partir da análise do programa Portugal Acolhe - Português para Todos, realizada por Cabete (2010), e de dados de interação em sala de aula do projeto de extensão Português Brasileiro para Migração Humanitária, da Universidade Federal do Paraná, apresento uma discussão sobre como algumas políticas linguísticas para migração e refúgio pautadas em ideologias homogeneizantes podem reforçar práticas assimilacionistas e de silenciamento de agências, apesar de serem justificadas por pressupostos liberais de inclusão e de igualdade.
\end{abstract}

PALAVRAS-CHAVE: Língua de Acolhimento; Ensino de Língua Adicional; Inserção Social.

ABSTRACT: Considering the intrinsic relation between power, language and identity, this article focuses on the concept of welcoming language (ANÇÃ , 2008; CABETE, 2010; GROSSO, 2010), discussing what teaching policies and practices may be linked to it by taking its underlying theoretical-ideological positions into account. Drawing on the analysis of the program Portugal Acolhe - Português para Todos conducted by Cabete (2010) and on some classroom interaction data from the extension project Brazilian Portuguese for Humanitarian Migration, of the Federal University of Paraná, I present a discussion on how some linguistic policies for migration and refuge based on homogenizing ideologies may reinforce assimilationist and agency-silencing practices, even though they are justified by liberal assumptions of inclusion and equality.

KEYWORDS: Welcoming Language; Additional Language Teaching; Social Insertion.

\footnotetext{
${ }^{1}$ Doutoranda em Linguística Aplicada. Email: renatafma@gmail.com .
} 
REVISTA X, Curitiba, volume 13,n.1, p. 35-56, 2018.

Dossiê Especial: Português como Língua Adicional em contextos de minorias:

(co)construindo sentidos a partir das margens

BIZON \& DINIZ (Orgs.)

\section{INTRODUÇÃO}

Este artigo é parte de minha dissertação de mestrado ${ }^{2}$ cujo objetivo central foi compreender como migrantes haitianos e refugiados sírios - meus alunos no projeto de extensão Português Brasileiro para Migração Humanitária (PBMIH) da Universidade Federal do Paraná (UFPR) - representavam sua agentividade, ou impossibilidade de agentividade, no novo contexto social, linguístico, cultural e político no qual se encontravam inseridos (ANUNCIAÇÃO, 2017). Neste recorte que ora apresento, gostaria de discutir como algumas políticas e ideologias linguísticas para migração e refúgio podem reforçar práticas assimilacionistas e de silenciamento de agências, apesar de serem justificadas por pressupostos liberais de inclusão e de igualdade.

Partindo dos pressupostos de que ensinar é um ato político (FREIRE, 2011) e de que tanto língua quanto identidade são construídas por relações de poder entre campos discursivos (CUCHE, 1999; SILVA, 2000; FOUCAULT, 2005), entende-se que o ensino de $\mathrm{PLA}^{3}$ deve ajudar alunos migrantes e refugiados a utilizarem o português com agentividade para enfrentar os desafios com que se deparam no seu dia a dia no Brasil. Proponho, assim, que cursos de português contemplem, no seu planejamento, discussões acerca de temas que, da perspectiva dos alunos migrantes e refugiados, sejam relevantes para a sua inserção na sociedade brasileira.

Outro fator a ser considerado em um curso de PLA para esse público, que se pretenda crítico e socialmente responsável, diz respeito à competência que se deseja que os alunos desenvolvam na língua-alvo. Equivocadamente, muitos idealizadores de cursos de português para falantes de outras línguas esperam que seus alunos adquiram um nível de proficiência equivalente ao de um "falante nativo" ideal da variedade considerada padrão dessa língua, sem entender que isso é uma impossibilidade, considerando, por exemplo, que esses alunos se apropriam da língua adicional a ela

\footnotetext{
2 ANUNCIAÇÃO (2017).

3 Conforme discussão feita por Schlatter \& Garcez (2009), que defendem que línguas adicionais representam acréscimos a repertórios linguísticos variados dos aprendizes, opto pelo termo "Língua Adicional", e não "Língua Estrangeira" para fazer referência ao ensino e aprendizagem de português para migrantes e refugiados, pois, além de reconhecer a variedade de repertórios linguísticos dos alunos, reconhece-se que a língua portuguesa passa a ser parte desse repertório, que já não é uma língua do outro, mas uma língua a mais nos repertórios dos indivíduos.
} 
REVISTA X, Curitiba, volume 13,n.1, p. 35-56, 2018.

Dossiê Especial: Português como Língua Adicional em contextos de minorias:

(co)construindo sentidos a partir das margens

BIZON \& DINIZ (Orgs.)

incorporando aspectos de sua cultura interacional de origem como forma de constituir suas identidades linguísticas particulares (MAHER, 2007a), que podem, inclusive, incluir práticas transculturais ${ }^{4}$ (CÉSAR \& CAVALCANTI, 2007) e práticas translíngues $^{5}$ (CANAGARAJAH, 2013). Ao desconsiderar essas identidades linguísticas múltiplas, hibridizadas e fluidas, validam-se políticas e práticas de ensino de língua assimilacionistas, normatizadoras a partir dos padrões dominantes e homogeneizantes que regulam os espaços de enunciação (GUIMARÃES, 2002, 2015), transformando, portanto, essas identidades linguísticas em identidades linguísticas minoritarizadas (CAVALCANTI, 1999, 2011; CANAGARAJAH, 2004). Assim, as relações que alunos migrantes e refugiados estabelecem com as línguas de seu repertório comunicativo ${ }^{6}$ (RYMES, 2014), que passa, agora, a contar também com a língua portuguesa, são aspectos intervenientes importantes quando o que se deseja é oferecer a eles cursos de PLA que respeitem suas constantes reconstruções identitárias dos indivíduos na diáspora. ${ }^{7}$

Considerando essas implicações linguísticas, identitárias e políticas, proponho, neste artigo, uma reflexão sobre o conceito de língua de acolhimento, o qual, a meu ver, apresenta-se como um conceito já sloganizado ${ }^{1}$ (VIEBROCK, 2014) na área de PLA em contexto de migração e refúgio. A discussão proposta parte de uma perspectiva que considera os usos linguísticos dos indivíduos nos diferentes espaços de enunciação e se desenvolve em duas partes. Na primeira, teço uma breve análise do programa Portugal

\footnotetext{
${ }^{4}$ De acordo com César \& Cavalcanti (2007, p. 46), uma vez que o radical trans confere ao conceito de transculturalidade o sentido de multi e bidirecionalidade e de complementaridade, "é considerado mais apropriado para desnaturalizar as questões de hegemonia cultural."

${ }^{5}$ Segundo Canagarajah (2013), as práticas translíngues constituem-se na interação por meio do uso da língua(gem). Nessa perspectiva, as hibridizações linguísticas típicas de interações em contextos plurilíngues (codemeshing) não são percebidas como falta de conhecimento de língua, mas como o uso de "formas e normas que estão sempre em um estado de devir, abertas à reconstituição por meio de práticas socialmente situadas que estão em curso" (CANAGARAJAH, 2013, p. 70). (Tradução minha do original: "forms and norms as always in a state of becoming, open to reconstitution through ongoing socially situated practices.")

${ }^{6}$ De acordo com Rymes (2014, p. 9-10), repertórios comunicativos são "a coleção de maneiras pelas quais indivíduos utilizam língua(gem) e outros meios de comunicação (gestos, vestimentas, postura, acessórios) para funcionar nas múltiplas comunidades das quais ele participa". (Tradução minha do original: "the collection of ways individuals use language and other means of communication (gestures, dress, posture, accessories) to function in the multiple communities in which they participate".)

${ }^{7}$ É importante ressaltar que, apesar de as aulas de língua adicional se configurarem em espaços de práticas interacionais em que as identidades são negociadas, se reconhece que o processo de (re)negociação identitária na diáspora é muito amplo e extrapola os limites da sala de aula.
} 
REVISTA X, Curitiba, volume 13,n.1, p. 35-56, 2018.

Dossiê Especial: Português como Língua Adicional em contextos de minorias:

(co)construindo sentidos a partir das margens

BIZON \& DINIZ (Orgs.)

Acolhe - Português para Todos, a partir de dados apresentados por Cabete (2010); na segunda, analiso dados de interação de sala de aula, nos quais os alunos expõem algumas de suas ideologias linguísticas.

Para melhor compreender o contexto em que a pesquisa aqui descrita foi desenvolvida, convém conhecer, ainda que brevemente, o perfil dos alunos e do projeto de extensão do qual eles participam. ${ }^{8}$ Iniciado em novembro de 2013 a pedido da comunidade haitiana e da ONG Casa Latino-Americana (CASLA), o projeto de extensão da Universidade Federal do Paraná (UFPR), chamado Português Brasileiro para Migração Humanitária (PBMIH), conta hoje com professores voluntários com formação em ou acadêmicos de Letras que ensinam PLA para migrantes e refugiados, sobretudo haitianos e sírios. Tendo participado do PBMIH desde a primeira reunião com os professores voluntários, no fim de outubro de 2013, pude testemunhar a preocupação, sempre presente dos idealizadores do projeto, de oferecer um ensino de PLA que fosse socialmente responsável e que proporcionasse a inserção plena e cidadã dos recém-chegados. O PBMIH, assim como outros projetos de ensino de PLA em contexto de migração e refúgio, adota o conceito de "português como língua de acolhimento" - PLAc - (ANÇÃ, 2008; CABETE, 2010; GROSSO, 2010) como pressuposto teórico-metodológico.

Os dados apresentados neste artigo foram gerados durante as aulas ministradas por mim e mais duas colegas, aos sábados à tarde, no prédio da reitoria da UFPR, durante o primeiro semestre letivo de 2016. Já no início das aulas, grande parte da turma (de nível intermediário, formada exclusivamente por haitianos) manifestou seu interesse em realizar o Exame Nacional do Ensino Médio (ENEM) no final daquele ano. A partir dessa demanda apresentada pelos alunos, começamos a elaborar aulas que contemplassem as temáticas e o formato da prova de língua portuguesa do ENEM. Como veremos na análise, esse dado se mostrará muito relevante, pois os posicionamentos dos alunos com relação ao ENEM nos possibilitarão compreender algumas percepções de migrantes e refugiados acerca do processo de ensinoaprendizagem de PLA.

\footnotetext{
${ }^{8}$ Para mais informações sobre o projeto de extensão, consultar Gediel, Casagrande \& Kramer (2016).
} 
REVISTA X, Curitiba, volume 13, n.1, p. 35-56, 2018.

Dossiê Especial: Português como Língua Adicional em contextos de minorias:

(co)construindo sentidos a partir das margens

BIZON \& DINIZ (Orgs.)

Na seção a seguir, apresentarei o referencial teórico que subsidiará a discussão proposta neste artigo acerca do conceito língua de acolhimento. Três principais conceitos serão mobilizados: verticalidade (SANTOS, 2000); espaço de enunciação (GUIMARÃES, 2002); despossessão e não reconhecimento (BUTLER \& ATHANASIOU, 2013).

\section{GERENCIAMENTO DA ALTERIDADE E SILENCIAMENTO}

Os processos de migração e de refúgio são extremamente desafiadores e, por vezes, dolorosos para os indivíduos que os vivenciam, pois implicam tanto perdas de recursos materiais (bens de consumo, imóveis e dinheiro) e simbólicos (acesso às línguas mais prestigiadas em um dado espaço de enunciação, não reconhecimento de sua educação formal), como afirma Norton (2013), quanto violências simbólicas causadas por racialização e marginalização de grupos étnicos e pela normatização homogeneizante e assimilacionista de modos de ser e de saber. Esses processos, que Butler \& Athanasiou (2013) chamam de despossessão, podem provocar altos níveis de estresse no indivíduo, pois exigem dele uma postura reflexiva constante diante do novo e do outro.

Considerando que identidade é uma prática discursiva socialmente construída, é importante nos perguntarmos o que ocorre quando se reduz o indivíduo (um "quem”) a uma categoria (um “o que”): índio, negro, migrante, refugiado. Essa concepção abstrata do outro, baseada em senso comum, generalizações e estereótipos, é extremamente perigosa. De acordo com Guimarães (2002, p. 18), nas sociedades, a enunciação é estratificada, isto é, constituída por espaços de enunciação nos quais as línguas "se dividem, redividem, se misturam, desfazem, transformam por uma disputa incessante. São espaços 'habitados' por falantes, ou seja, por sujeitos divididos por seus direitos ao dizer e aos modos de dizer". Essa divisão política dos direitos e dos modos de dizer também pode ser notada em contextos de migração e de refúgio, que, como outros, são espaços estratificados em função da posição que os sujeitos ocupam, permitindo ou não sua inserção em certos espaços. Infelizmente, assim como ocorre com outros grupos 
REVISTA X, Curitiba, volum e 13,n.1, p. 35-56, 2018.

Dossiê Especial: Português como Língua Adicional em contextos de minorias:

(co)construindo sentidos a partir das margens

BIZON \& DINIZ (Orgs.)

minoritarizados, a reificação de sujeitos migrantes e refugiados (imposta por discursos hegemônicos) limita os espaços por onde podem transitar esses indivíduos e, consequentemente, a possibilidade de exercício de sua agentividade e inserção mais igualitária na sociedade.

Essa limitação (como silenciamento), bem como a homogeneização de populações minoritarizadas operam no que Santos (2000) chamou de verticalidade, pois são fundadas em preceitos normatizadores do Estado neoliberal. Esse cria mecanismos de controle social para produzir padrões de comportamento, regulando a distribuição de vulnerabilidade, destruindo e esgotando economicamente a subsistência de grupos que não se encaixam nos padrões hegemônicos, ao decidir quais vidas podem ser consideradas devidamente humanas (properly human). Grupos minoritarizados são assim destituídos de sua humanidade (humanness), têm sua vida precarizada por preceitos normatizadores impostos pela lógica neoliberal e suas identidades reduzidas a categorias totalizantes (mulher, negro(a), pobre, migrante, indígena, LGBT). Butler \& Athanasiou (2013, p. 31-32, grifo meu) explicam essa relação entre neoliberalismo e alocação de humanidade:

\begin{abstract}
Essas formas de poder colonialmente constituídas, racializadas e sexualizadas, que estão circunscritas nas economias de propriedadepropriedade do lugar e do sujeito modernos, produzem incomensuráveis onto-epistemologias de humanidade e não humanidade, possessão e despossessão, viabilidade e inviabilidade. Quando se trata "do humano", a questão que deve ser abordada constante e veementemente é a alocação diferencial de humanidade: a fronteira de posição perpetuamente deslocável e variável entre aqueles que são considerados devidamente humanos e aqueles que não são, aqueles que têm o direito a uma vida longa e aqueles relegados à morte lenta. ${ }^{9}$
\end{abstract}

A desumanização (non-humanness), derivada da reificação de identidades, implica a distribuição de vulnerabilidade e a precarização de vidas em processos de

\footnotetext{
9 Tradução minha do original: "Such racialized and sexualized colonially inscribed forms of power involved in the property-propriety economies of the modern subject and place produce incommensurate onto-epistemologies of humanness and non-humanness, possession and dispossession, livability and unlivability. When it comes to 'the human', the matter that must be addressed constantly and forcefully is the differential allocation of humanness: the perpetually shifting and variably positioned boundary between those who are rendered properly human and those who are not, those who are entitled to a long life and those relegated to slow death."
} 
REVISTA X, Curitiba, volum e 13,n.1, p. 35-56, 2018.

Dossiê Especial: Português como Língua Adicional em contextos de minorias:

(co)construindo sentidos a partir das margens

BIZON \& DINIZ (Orgs.)

depossessão e de não reconhecimento (BUTLER \& ATHANASIOU, 2013).

De acordo com Butler \& Athanasiou (2013, p. 2), ser despossuído envolve a marginalização de indivíduos, mecanismos de poder normativos e normatizadores que "definem a inteligibilidade cultural e que regulam a distribuição de vulnerabilidade"10. O termo despossessão pressupõe, portanto, a ideia de privação ou alienação de recursos materiais e simbólicos que pertenceriam ao sujeito por direito. Além disso, a despossessão opera como um mecanismo de controle autoritário, violento e paternalista por meio da imposição de práticas regulatórias de inserção de indivíduos na sociedade. Como argumentam Butler \& Athanasiou (2013, p. 11, grifo meu):

\begin{abstract}
Despossessão funciona como um aparato de controle e de apropriação autoritário e frequentemente paternalista do espaço, da mobilidade, da afetividade, da potencialidade e da relacionalidade de sujeitos (neo)colonizados. Em contextos como esses, "despossessão" oferece linguagem para expressar experiências de despertencimento, ocupação, destruição de lares e de laços sociais, incitação a [construção] de identidades "autênticas", vitimização humanitária, inviabilidade e lutas por autodeterminação. [...] $\mathrm{Na}$ atual economia de mercado do capitalismo neoliberal e da "debitocracia", despossessão significa a apropriação violenta do trabalho e o esgotamento de corpos trabalhadores e não trabalhadores. ${ }^{11}$
\end{abstract}

Operando dentro de uma lógica regulatória e normatizadora, a despossessão impõe uma "condição de autonomia heteronômica" (BUTLER \& ATHANASIOU, 2013, p. 9). Considerando que a heteronomia, na filosofia kantiana, significa sujeição do indivíduo à vontade de terceiros ou de uma coletividade, a condição de autonomia heteronômica não é, de fato, uma condição de autonomia, uma vez que ela se constitui dentro de um regime de regras e normas impostas por terceiros. Nesse sentido, essa autonomia condicionada (porque é heteronômica) está muito mais próxima de ser

\footnotetext{
10 Tradução minha do original: "Powers that define cultural intelligibility and that regulate the distribution of vulnerability”.

11 Tradução minha do original: "Dispossession works as an authoritative and often paternalistic apparatus of controlling and appropriating the spaciality, mobility, affectivity, potentiality, and relationality of (neo-)colonized subjects. In such contexts, 'dispossession' offers language to express experiences of uprootedness, occupation, destruction of homes and social bonds, incitation to 'authentic' self-identities, humanitarian victimization, unlivability, and struggles for self-determination. [...] In today's global Market economy of neoliberal capitalism and 'debtocracy', dispossession signifies the violent appropriation of labor and the wearing out of laboring and non-laboring bodies."
} 
REVISTA X, Curitiba, volum e 13,n.1, p. 35-56, 2018.

Dossiê Especial: Português como Língua Adicional em contextos de minorias:

(co)construindo sentidos a partir das margens

BIZON \& DINIZ (Orgs.)

considerada uma condição de anomia (MERTON, 1938) do que de autonomia per se, sobretudo se se compreender que muitas dessas regras e normas são formuladas e impostas por sociedades e governos que operam dentro da lógica verticalizada, desumanizadora e precarizadora do neoliberalismo.

É possível identificar a defesa dessa condição de autonomia heteronômica em discursos sobre integração ${ }^{12}$ de populações migrantes e refugiadas, sobretudo em países do Norte que defendem que, para terem acesso à saúde, à educação e ao trabalho legalizado, recém-chegados devem conhecer e praticar a cultura e a língua do país receptor, adequando seus comportamentos, corpos e linguagem, tornando-os apropriados (appropriate) para poderem ser reconhecidos como indivíduos que desfrutam de direitos e de recursos materiais e simbólicos. Paradoxalmente, ao invés de promoverem o acesso ao estado de bem-estar social e à inserção de migrantes e refugiados, essas regras e normas do discurso neoliberal reforçam violência simbólica contra grupos minoritarizados. Nas palavras de Butler \& Athanasiou (2013, p. 77, grifo meu):

É um momento, como um dos muitos momentos das políticas migratórias, no qual a exigência por obediência à norma que rege aceitabilidade e inteligibilidade do sujeito pode levar $\mathbf{e}$, de fato, leva à desconstituição do sujeito pela própria lei. ${ }^{13}$

A partir de uma perspectiva liberal, o reconhecimento opera "como um ideal regulatório e uma forma de gerenciamento da alteridade" (BUTLER \& ATHANASIOU, 2013, p. 75) ${ }^{14}$ e acaba reproduzindo as desigualdades sociais e reforçando o mito da coesão nacional ("um país de todos"15, onde há oportunidades iguais e onde não há racismo). De acordo com Butler \& Athanasiou (2013), o reconhecimento tem sua origem no conceito hegeliano de "luta pelo reconhecimento" (Kampf um Anerkennung),

\footnotetext{
${ }^{12}$ Utilizo o termo integração propositalmente, pois reconheço nele uma conotação assimilacionista.

13 Tradução minha do original: "It is a moment, like any number of moments within immigration politics, when the demand to comply with the norm that governs the acceptability and intelligibility of the subject can and does lead to the deconstitution of the suject by the law itself."

14 Tradução minha do original: "as a regulatory ideal and form of managing alterity".

15 Slogan do primeiro governo da Presidenta Dilma Rousseff (2010-2014), período que coincide com a intensificação da chegada de migrantes e refugiados ao país.
} 
REVISTA X, Curitiba, volume 13, n.1, p. 35-56, 2018.

\section{Dossiê Especial: Português como Língua Adicional em contextos de minorias:}

(co)construindo sentidos a partir das margens

BIZON \& DINIZ (Orgs.)

o qual se apoia na ideia de que o não cumprimento das regras de reconhecimento oferecidas pela sociedade teria como consequência a inviabilidade da sua vida. A aceitação das condições de reconhecimento e a adequação às relações de poder que constituem seus termos determinam a viabilidade do sujeito na sociedade. Pode-se dizer, portanto, que o reconhecimento é um processo de assimilação, na medida em que, para obtê-lo, o indivíduo se sujeita a regras e a termos impostos a ele por estratos hegemônicos. É nesse sentido que o termo "reconhecimento" está diretamente ligado ao termo "sobrevivência", pois, nas palavras de Butler \& Athanasiou (2013, p. 79), o primeiro "designa a situação na qual alguém é fundamentalmente dependente de termos que não escolheu para que possa emergir como um ser inteligível"16.

$\mathrm{O}$ reconhecimento, assim, constitui-se nas relações de poder intrínsecas às sociedades, tais como as questões de raça, classe, gênero, nacionalidade, razão pela qual a assimilação se transforma em mecanismo e pré-requisito para a sobrevivência na e à sociedade e aos seus poderes regulatórios.

É importante ressaltar que esses processos de despossessão e não reconhecimento são anteriores à questão do uso da língua adicional no contexto de migração e de refúgio, isto é, não são decorrentes, mas são agravados pelo não "domínio" da língua, conforme indiciam os dados que serão apresentados na última seção deste artigo. Isso ocorre porque, já de início, se esbarra em uma questão muito prática: interagir com outros. Muitos migrantes e refugiados que dão entrada no Brasil têm boa formação acadêmica, razão pela qual é provável que, em seu país de origem, muitos deles fizessem parte de um grupo de indivíduos com maior acesso a recursos materiais) e simbólicos. Ao chegarem ao Brasil, contudo, veem-se, frequentemente, destituídos desses recursos devido à condição de vulnerabilidade a que acabam submetidos pelos processos de despossessão e de não reconhecimento, que são agravados pelo não "domínio" da língua portuguesa.

Considerando essa relação entre despossessão, não reconhecimento e língua(gem) no contexto de migração e refúgio, proponho, na seção seguinte, uma

\footnotetext{
16 Tradução minha do original: "designates the situation in which one is fundamentally dependent upon
} terms that one never chose in order to emerge as an intelligible being." 
REVISTA X, Curitiba, volume 13, n.1, p. 35-56, 2018.

Dossiê Especial: Português como Língua Adicional em contextos de minorias:

(co)construindo sentidos a partir das margens

BIZON \& DINIZ (Orgs.)

análise do conceito língua de acolhimento desde sua origem portuguesa até a sua apropriação no contexto de migração e refúgio brasileiros.

\section{AFINAL, O QUE SE ESTÁ ENTENDENDO POR “ACOLHIMENTO”?}

Cada vez mais utilizado no contexto de migração e refúgio, o termo língua de acolhimento merece problematização. Como veremos mais adiante, tal termo, empregado no âmbito da política linguística do Estado português, é simbolicamente bastante violento, pois o acesso a direitos, como nacionalidade e autorização de residência permanente, é condicionado à comprovação de proficiência em língua portuguesa.

O ensino de Português como Língua de Acolhimento, com material didático e currículo padronizado, faz parte da política de Estado português, presente em todo o território. O programa, chamado Portugal Acolhe - Português para Todos, foi criado no âmbito do Plano de Integração dos Imigrantes, publicado em 2007, e é uma iniciativa conjunta do Ministério do Trabalho, da Solidariedade Social, do Ministério da Educação e da Presidência do Conselho de Ministros. Os cursos de Língua de Acolhimento estão organizados em três percursos de formação, divididos pelo que Cabete (2010) chama de “áreas de competência": língua portuguesa, cidadania e português técnico.

O percurso de língua portuguesa é subdividido em A e B - correspondentes ao A e ao B do Quadro Europeu Comum de Referência para Línguas -, nos quais se objetiva trabalhar questões linguísticas a partir de abordagem comunicativa ${ }^{17}$. O percurso A é subdividido em A1, A2(1) e A2(2), com 50 horas cada, que "visam a aquisição e o reforço de competências no domínio elementar da língua portuguesa" (CABETE, 2010,

\footnotetext{
17 A divisão do percurso do Portugal Acolhe em módulos de língua e módulos de cultura e cidadania representa outro aspecto a ser considerado na concepção do conceito de língua de acolhimento. A separação entre o ensino de língua e o ensino de cultura e de cidadania (como se fosse possível compartimentalizar a língua(gem) e os indivíduos nela implicados) evidencia uma concepção de língua dissociada das práticas sociais, não reconhecendo que a língua(gem) se constitui nessas contingências e que ela é permeada por disputas de poder e de saber.
} 
REVISTA X, Curitiba, volume 13, n.1, p. 35-56, 2018.

Dossiê Especial: Português como Língua Adicional em contextos de minorias:

(co)construindo sentidos a partir das margens

BIZON \& DINIZ (Orgs.)

p. 59). O percurso B, por sua vez, subdividido em B1 e B2, ainda não havia sido implementado até o momento da defesa da dissertação de Cabete $(2010)^{18}$.

No que diz respeito à "área de competência de Cidadania", é ofertado um curso de 50 horas, que "tem como fim a aquisição e o reforço de competências no domínio da cidadania, particularmente, ao nível dos direitos e deveres dos cidadãos/trabalhadores" (CABETE, 2010, p. 60, grifo meu). O terceiro percurso de formação que integra o programa Portugal Acolhe - Português para Todos é o Português Técnico, com 25 horas, cujo objetivo é "um melhor acesso e integração no mercado de trabalho" (CABETE, 2010, p. 60). Como se pode notar, esse último nível do percurso do programa Portugal Acolhe concentra seu foco em conteúdos que facilitam a inserção do migrante ou refugiado no mercado de trabalho português.

Como argumentarei mais adiante, é problemático transpor o conceito europeu de língua de acolhimento ao contexto brasileiro de migração e de refúgio. Quando condiciona a inserção social do indivíduo no novo país de domicílio ao "domínio" da língua nacional, esse conceito apresenta uma visão reificada de língua, que tem sua origem na criação dos Estados nacionais, defendendo a ideia de que o pertencimento a uma comunidade constitui-se no "domínio" da língua nacional (MAKONI \& PENNYCOOK, 2005).

Considero que a adoção do termo língua de acolhimento deve ser problematizada, pois, além de ter sido transposto do contexto político-linguístico português, seus pressupostos se baseiam na ideia de um multiculturalismo liberal (MAHER, 2007a), o qual reforça processos de despossessão e de não reconhecimento, ao reificar diferenças e classificar algumas experiências e vivências culturais como mais autênticas ou superiores a outras. Transplantada ao contexto brasileiro, essa concepção, que condiciona o conhecimento de uma determinada língua como pressuposto de nacionalidade e de adequação social, reforça o mito e a ideologia de que o Brasil é um país monolíngue e linguisticamente homogêneo, como argumentam Maher (2007a) e César \& Cavalcanti (2007).

\footnotetext{
${ }^{18}$ Não tenho informações se o percurso B foi implementado.
} 
REVISTA X, Curitiba, volume 13, n.1, p. 35-56, 2018.

Dossiê Especial: Português como Língua Adicional em contextos de minorias:

(co)construindo sentidos a partir das margens

BIZON \& DINIZ (Orgs.)

A divisão do percurso do Portugal Acolhe em módulos de língua e módulos de cultura e cidadania representa outro aspecto a ser considerado na concepção do conceito de língua de acolhimento. A separação entre o ensino de língua e o ensino de cultura e de cidadania (como se fosse possível compartimentalizar a língua(gem) e os indivíduos nela implicados) evidencia uma concepção de língua dissociada das práticas sociais, não reconhecendo que a língua(gem) se constitui nessas contingências e que ela é permeada por disputas de poder e de saber.

Outro fator a ser analisado diz respeito ao condicionamento da conclusão dos cursos e obtenção de certificação de língua portuguesa como parte de uma política linguística nacional para que migrantes e refugiados tenham acesso a direitos (ao emprego legalizado, por exemplo). Assim, o programa Portugal Acolhe apresenta características de políticas de reconhecimento que se aproximam de perspectivas assimilacionistas, uma vez que promove uma condição de autonomia heteronômica. Se, por um lado, "o direito ao ensino/aprendizagem da língua de acolhimento possibilitará o uso dos outros direitos, assim como o conhecimento do cumprimento dos deveres que assistem a qualquer cidadão" (GROSSO, 2010, p. 69), por outro, esses valores liberais são colocados em prática por meio de políticas assimilacionistas, padronizadas e normativizadoras, com emissão de certificados que condicionam o acesso a direitos civis, como explica Cabete (2010, p. 61, grifo meu):

Com a obtenção do certificado do curso, os participantes ficarão dispensados da realização de testes comprovativos do conhecimento da língua e assim poderem [sic] vir a ter acesso à nacionalidade, à autorização de residência permanente e/ou ao estatuto de residente de longa duração.

Reconhecendo, como apontado por Grosso (2010, p. 70, grifo meu), a existência de um "contexto da cultura dominante, com uma estrutura etnocêntrica que desconhece as características e a realidade do público-alvo", é necessário identificar quais sãos os mecanismos de dominação etnocêntrica a que estão sujeitos migrantes e refugiados no novo país de domicílio. É necessário, portanto, avaliar em que bases essa "partilha e compreensão de comportamentos, atitudes e valores" (GROSSO, 2010, p. 70) são negociados. Como discutem Butler \& Athanasiou (2013, p. 76), "o que o 
REVISTA X, Curitiba, volum e 13,n.1, p. 35-56, 2018.

Dossiê Especial: Português como Língua Adicional em contextos de minorias:

(co)construindo sentidos a partir das margens

BIZON \& DINIZ (Orgs.)

estado-nação liberal está reconhecendo e o que ele está deixando de reconhecer quando admite [a existência da] diferença? O que ele está produzindo, o que ele está afirmando e o que ele está violando?"19.

Albán (2005, apud ALBÁN, 2012, p. 61) também argumenta que dificilmente se podem estabelecer diálogos interculturais simétricos em sociedades, pois

[...] sem levar em conta as condições de diálogo e os termos em que isso ocorre, permanecem intactas as assimetrias historicamente construídas, produzindo um diálogo entre um projeto hegemônico e as culturas subalternizadas que devem assimilar-se ao discurso estabelecido pelo hegemônico, assim [...] 'é impossível pensar uma sociedade intercultural enquanto prevaleçam formas e práticas de racialização e exclusão, bem como discursos que subalternizem ou minorizem setores da população", ${ }^{20}$

Tal concepção multicultural liberal (MAHER, 2007a), além de reforçar a reificação da cultura dos sujeitos envolvidos e a ideia de que as construções culturais não podem influenciar umas às outras, tem como consequência o apagamento de subjetividades culturais híbridas ou em processo de hibridização, que convivem em contextos superdiversos (de migração e de refúgio), tornando-as padronizadas a partir de uma perspectiva etnocêntrica. Nesse sentido, concordo com Bizon e Camargo (2018, p. 716) quando as autoras defendem que as políticas de acolhimento e de ensino de PLA nesse contexto deveriam ser proativas, isto é, construídas "no diálogo possível entre os agenciamentos verticais e horizontais" ao invés de reativas, isto é, formuladas a partir de resoluções normativas, verticalizadas. Ao desconsiderar essas identidades culturais múltiplas, hibridizadas e fluidas, validam-se políticas e práticas de ensino de língua assimilacionistas, normatizadoras a partir dos padrões dominantes e homogeneizantes que regulam os espaços de enunciação (GUIMARÃES, 2002, 2015), transformando,

\footnotetext{
19 Tradução minha do original: "What is the liberal nation-state recognizing and what is it misrecognizing when it acknowledges difference? What is it producing, what is it affirming, and what is it violating?".

20 Tradução minha do original: "[...] sin que se tengan en cuenta las condiciones del diálogo y los términos en que este se produce lo que puede dejar intactas las asimetrías construidas históricamente y el diálogo se produzca entre un proyecto hegemónico y una culturas subalternizadas que deben asimilarse a la conversación que lo hegemónico establece, así las cosas [...] 'es imposible pensarse una sociedad intercultural mientras prevalezcan formas y prácticas de racialización y exclusión, al igual que discursos que subalternicen o minoricen sectores de la población"”.
} 
REVISTA X, Curitiba, volume 13, n.1, p. 35-56, 2018.

Dossiê Especial: Português como Língua Adicional em contextos de minorias:

(co)construindo sentidos a partir das margens

BIZON \& DINIZ (Orgs.)

portanto, essas identidades linguísticas em identidades linguísticas minoritarizadas (CAVALCANTI, 1999, 2011).

A literatura sobre ensino de língua adicional em contexto de migração e de refúgio (VITANOVA, 2005; GROSSO, 2010; NORTON, 2013) atesta que a falta de proficiência é percebida como um entrave à inserção na sociedade, inclusive no que diz respeito ao direito à educação. Na próxima seção, apresentarei um trecho de uma conversa entre mim, três alunos e uma colega professora, nos minutos iniciais da aula de português. A partir da análise desses dados, pretende-se demonstrar como o acesso a um direito constitucional garantido a brasileiros e estrangeiros - o direito à educação - é limitado pelo não "domínio" do português, agravando os processos de despossessão e não reconhecimento e a distribuição de vulnerabilidade nas comunidades migrantes e refugiadas.

\section{"NÃO TEM DISTINÇÃO ENTRE BRASILEIROS E ESTRANGEIROS, PORÉM..."}

O título desta seção é o recorte de uma fala de Olivier ${ }^{21}$ (nome fictício), haitiano de 35 anos, aluno do curso de PLA oferecido pelo PBMIH, na UFPR, e indicia sua percepção de que há distinção entre brasileiros e estrangeiros. O trecho que se segue é a transcrição dos minutos iniciais da aula do dia 11 de junho de 2016, durante uma discussão, em sala de aula, entre Olivier e seus colegas Joseph e Ronald (também haitianos de da mesma faixa etária). Nesse momento, os três alunos estavam discutindo seus direitos no Brasil, quando Olivier começa a argumentar sobre o tema com base nos seus conhecimentos sobre a Constituição de 1988:

Joseph - Você está vivendo em um país, você tem que saber os direitos que você tem, né?

Olivier - Cara, se você viu, a Constituição Brasileira de 1988 é uma das melhores, das mais belas, que existem na terra, mas vai ver na prática, vai lá na prática, vai ver!

Ronald - Não, as coisas estavam lá no tempo da ditadura. Agora não está na ditadura, as leis têm que mudar também.

Renata - É, mas a Constituição não foi feita na ditadura, foi feita depois, o problema, Ronald, é o Estatuto do Estrangeiro. Esse foi feito na ditadura.

\footnotetext{
${ }^{21}$ Os nomes de todos os participantes, com exceção do meu, são fictícios.
} 
REVISTA X, Curitiba, volume 13,n.1,p. 35-56, 2018.

Dossiê Especial: Português como Língua Adicional em contextos de minorias:

(co)construindo sentidos a partir das margens

BIZON \& DINIZ (Orgs.)

Olivier - É, o que que a Constituição de 88 diz: todas as pessoas, inclusivo os estrangeiros que estão vivendo no país, têm direito, como moradia, eles têm educação, tal, tal, tal... não tem distinção entre brasileiros e estrangeiros, porém... eles vão dizer, o estrangeiro tem que ter domínio de língua portuguesa, tal, tal, tal... tal, tal, tal...

$[\ldots]$

Olivier - Não... isso é, depois de uma coisa dizer, ó: vai entrar, vai ingressar, porque as faculdades estabeleceram as normas internas para que o estrangeiro ingresse nas universidades. Isso que eu estou dizendo.

A Constituição da República Federativa do Brasil (BRASIL, 1988) assegura que "todos são iguais perante a lei, sem distinção de qualquer natureza" (Art. 5, caput); porém, Olivier e Ronald percebem que, de fato, há distinção, quando afirmam: "mas vai ver na prática, vai lá na prática, vai ver!" e "as leis têm que mudar também”. Além disso, o fato de Ronald confundir a Constituição Federal de 1988 (promulgada após a última ditadura militar brasileira) com o restritivo Estatuto do Estrangeiro (Lei n. 6.815/1980) é outro indício de que esse pressuposto de igualdade não é percebido como válido para todos. Essa percepção dos alunos confirma que tanto recursos materiais quanto simbólicos são distribuídos de maneira irregular nas sociedades (SANTOS, 2002; BUTLER \& ATHANASIOU, 2013; NORTON, 2013). Os dados acima indicam também que essa distribuição irregular é agravada pelo não "domínio" da língua portuguesa quando Olivier afirma: "não tem distinção entre brasileiros e estrangeiros, porém... eles vão dizer, o estrangeiro tem que ter domínio de língua portuguesa, tal, tal, tal... tal, tal, tal...”. Ao fazer tal afirmação, Olivier assume equivocadamente que o "domínio" do português seja uma exigência imposta ao estrangeiro pelo Estado brasileiro. Olivier justifica seu entendimento: "não, isso é depois de uma coisa dizer, ó: vai entrar, vai ingressar, porque as faculdades estabeleceram as normas internas para que o estrangeiro ingresse nas universidades. Isso que eu estou dizendo." Isso indicia a importância atribuída à língua portuguesa pelos migrantes como um instrumento de inserção no novo país de domicílio. Ao afirmar que "eles [a $\mathrm{CF} / 88]$ vão dizer, o estrangeiro tem que ter 
REVISTA X, Curitiba, volume 13,n.1, p. 35-56, 2018.

Dossiê Especial: Português como Língua Adicional em contextos de minorias:

(co)construindo sentidos a partir das margens

BIZON \& DINIZ (Orgs.)

domínio de língua portuguesa ${ }^{22}$, tal, tal, tal...”, Olivier indicia sua percepção de que, sem o português, o exercício pleno de cidadania fica comprometido, uma vez que os processos de despossessão e de não reconhecimento são agravados pelo não "domínio" da língua portuguesa. Nesse sentido, pode-se afirmar que a normatização da igualdade se transforma em uma ferramenta de "gerenciamento de alteridade" (BUTLER \& ATHANASIOU, 2013, p. 75), uma vez que essa igualdade normatizada neutraliza diferenças de raça, de gênero, de classe social e de nacionalidade, como se os mesmos direitos estivessem igualitariamente disponíveis a todos, independentemente de quem ou como sejam, reforçando o perverso mito da igualdade de oportunidades.

Quando esses dados forma gerados, a nova Lei de Migração (Lei 13445/2017) ainda não havia sido aprovada. A nova lei, assim como a anterior (Lei 6815/1980, conhecida como Estatuto do Estrangeiro), condicionam a obtenção da nacionalidade brasileira pelo estrangeiro à capacidade de "comunicar-se em língua portuguesa". O Estatuto do Estrangeiro de 1980, contudo, não definia quais seriam os critérios para avaliar tal capacidade de comunicação em português, como explicam Camargo e Anunciação (em fase de elaboração):

\begin{abstract}
A legislação anterior, que vigorou de agosto 1980 até maio de 2017, exigia que o naturalizando demonstrasse a capacidade de "ler e escrever a língua portuguesa, consideradas as condições do naturalizando' (BRASIL. Lei no. 6.815/1980, art. 112, IV), por meio da 'leitura de trechos da Constituição' (Decreto no. 86.715/81, art. 129, I) para um juiz, durante a audiência. Conforme pontuam Dias e Pinto (2017), não havia um sistema de critérios comuns para fins avaliativos, tornando a avaliação discricionária.
\end{abstract}

Nesse sentido, a regulamentação da nova Lei de Migrações (Portaria Interministerial $\mathrm{N}^{\mathrm{o}}$. 11, de 03 de maio de 2018) que instituiu o exame Celpe-Bras como instrumento de avaliação da capacidade de comunicação do migrante em português, poderia ser considerado um avanço no que diz respeito à padronização da avaliação dos recursos linguísticos dos candidatos à naturalização. Camargo e Anunciação (em fase de elaboração), contudo, argumentam, ao analisar a estrutura e o construto teórico do exame, que tal determinação reforça mecanismos de despossessão e de não

22 Essa importância atribuída à língua portuguesa parece estar diretamente ligada à ideologia de monolinguismo que constitui o imaginário nacional, segundo o qual um país = uma nação = uma língua (MAHER, 2007a; CANAGARAJAH, 2013). 
REVISTA X, Curitiba, volume 13,n.1, p. 35-56, 2018.

Dossiê Especial: Português como Língua Adicional em contextos de minorias:

(co)construindo sentidos a partir das margens

BIZON \& DINIZ (Orgs.)

reconhecimento aos quais populações migrantes são frequentemente submetidas e que, como dito anteriormente, são anteriores ao "domínio" do português.

Nesse sentido, a aprendizagem do português opera, ao mesmo tempo, como um mecanismo de reconhecimento que reforça a assimilação por meio de regras e normas (quando se torna uma exigência para o acesso à universidade e à obtenção da nacionalidade brasileira) e como um instrumento de prática de (re)existência frente ao não reconhecimento de direitos (quando o migrante ou refugiado expressa sua agentividade na língua adicional). Nesse último fator reside a importância de práticas reflexivas (CÉSAR \& CAVALCANTI, 2007; JORDÃO, 2013) e proativas (BIZON \& CAMARGO, 2017) de ensino-aprendizagem de língua adicional que considerem as implicações identitárias, políticas e sociais do contexto de migração e de refúgio para a inserção mais igualitária dos recém-chegados na sociedade brasileira.

É importante ressaltar também que os dados acima indiciam que a sala de aula em contexto de migração e de refúgio pode ser um espaço em que práticas de (re)existência aparecem com certa frequência. Isso evidencia a necessidade da concepção - a partir de uma perspectiva crítica (que considerem tanto os processos de despossessão e de não reconhecimento como as práticas de (re)existência) - de práticas docentes de PLA que, de maneira mais flexível, se adaptem às necessidades apresentadas pelos alunos, à medida que elas vão aparecendo ou sendo externalizadas.

\section{CONSIDERAÇÕES FINAIS}

A despossessão e o não reconhecimento como violências simbólicas operam como um instrumento de manutenção do status quo. A submissão de migrantes e refugiados a esses processos intensifica a reificação de suas subjetividades, despojandolhes de sua humanidade (humanness), silenciando suas identidades múltiplas e fluidas e limitando o acesso a espaços mais privilegiados, limitando, por conseguinte, suas possibilidades de exercício de agência nas interações sociais, especialmente em contextos institucionalizados e mais hierarquizados (como no contato com a burocracia Estatal ou nas interações no ambiente de trabalho). A consequência desses processos é o 
REVISTA X, Curitiba, volume 13,n.1, p. 35-56, 2018.

Dossiê Especial: Português como Língua Adicional em contextos de minorias:

(co)construindo sentidos a partir das margens

BIZON \& DINIZ (Orgs.)

aprofundamento das assimetrias e da marginalização de populações migrantes e refugiadas no Brasil, como se pôde observar a partir de dos dados apresentados.

Diante da violência simbólica sofrida pela população migrante e refugiada, parece necessário discutir um conceito bastante popular no ensino de línguas nesse contexto: o de língua de acolhimento. Acolhimento é uma palavra de conotação positiva. Apesar de existirem políticas linguísticas específicas para o contexto de migração e refúgio em diferentes lugares do globo, como o Portugal Acolhe, é necessário questionar em que medida elas não reproduzem essas mesmas relações assimétricas de poder e de saber. Neste artigo, discuti como o conceito - já sloganizado (VIEBROCK, 2014) pela literatura especializada - de língua de acolhimento, enquanto uma construção da política linguística do Estado Português, precisa ser ressignificado. Além de ter sido transposto do contexto político-linguístico português, os pressupostos do termo língua de acolhimento baseiam-se na ideia de um multiculturalismo liberal (MAHER, 2007a), o qual reforça processos de despossessão e de não reconhecimento ao desconsiderar as relações de poder que constituem as relações entre culturas, tornando umas hegemônicas e outras, subalternizadas.

Em vez de se pensar em português como língua de acolhimento como um conceito acabado, seria interessante considerar políticas de acolhimento linguístico que envolvem a educação da sociedade para construção de relações interculturais mais inclusivas, como propõem Maher (2007b), Albuquerque, Gabriel \& Anunciação (2016) e Lopez (2016), e o ensino crítico de língua adicional (JORDÃO, 2013) em uma perspectiva transcultural (CÉSAR \& CAVALCANTI, 2007) e translíngue (CANAGARAJAH, 2013), reconhecendo que a língua(gem) é um espaço de luta, resistência e (re)existência (ANUNCIAÇÃO, 2017) em que agências e identidades são performatizadas a partir da interação dialógica entre sujeitos sociais e históricos.

Faz-se necessário investigar, portanto, como os atores envolvidos com o ensino de PLA em contexto de migração e de refúgio o compreendem enquanto política linguística, considerando as características sócio-históricas e políticas do Brasil, para discutir o termo língua de acolhimento a partir dos usos linguísticos dos indivíduos em diferentes contextos. Assim, ao refletir sobre língua de acolhimento, é indispensável 
REVISTA X, Curitiba, volume 13,n.1, p. 35-56, 2018.

Dossiê Especial: Português como Língua Adicional em contextos de minorias:

(co)construindo sentidos a partir das margens

BIZON \& DINIZ (Orgs.)

refletir sobre os usos linguísticos de fato e observar em que medida a língua que acolhe não é a mesma que silencia.

\section{REFERÊNCIAS}

ANUNCIAÇÃO, R. Somos mais que isso: Práticas de (Re)existência de Migrantes e Refugiados Frente à Despossessão e ao Não Reconhecimento. Dissertação (Mestrado em Linguística Aplicada) - Universidade Estadual de Campinas, Campinas, 2017.

ALBÁN, A. El desencanto o la modernidad hecha trizas. Una mirada a las racionalidades en tensión. In: WALSH, Catherine (Org.). Pensamiento crítico y matriz (de) colonial reflexiones latinoamericanas. Quito, Ecuador: Abya Yala, 2005.

Tiempos de zango y de guampín: transformaciones gastronómicas, territorialidad y re-existencia socio-cultural en comunidades Afro-descendientes de los valles interandinos del Patía (Sur de Colombia) y Chota (Norte del Ecuador), siglo XX. Tese (Doctorado en Estudios Culturales) - Universidad Andina Simón Bolívar, QuitoEcuador, 2007.

La educación intercultural ante el desplazamiento forzado: ¿Posibilidad o quimera?. [Con] textos, v. 1, n. 1, p. 55-66, 2012.

ALBUQUERQUE, J.; GABRIEL, M.; ANUNCIAÇÃO, R. O papel do entorno no acolhimento e na integração de populações migrantes para o exercício pleno da cidadania. In: GEDIEL, José Antônio; GODOY, Gabriel (Orgs.). Refúgio e hospitalidade. Curitiba: Kairós, 2016.

ANÇÃ, M.H. Língua portuguesa em novos públicos. Saber (e) Educar, n. 13, p. 71-87, 2008.

BIZON, A.C.C. Narrando o exame Celpe-Bras e o convênio PEC-G: a construção de territorialidades em tempos de internacionalização. Tese (Doutorado em Linguística Aplicada) - Instituto de Estudos da Linguagem/Universidade Estadual de Campinas, Campinas, 2013.

BIZON, A.C.C.; CAMARGO, H.R.E. Acolhimento e ensino da língua portuguesa à população oriunda de migração de crise no município de são Paulo: por uma política do atravessamento entre verticalidades e horizontalidades. In: BAENINGER, R; et al. (Orgs). Migrações Sul-Sul. Campinas, SP: Núcleo de Estudos de População "Elza Berquó" - Nepo/Unicamp, 2018.

BUTLER, J.; ATHANASIOU, A. Dispossession: the performative in the political. Hoboken: John Wiley \& Sons, 2013. 
REVISTA X, Curitiba, volume 13,n.1,p. 35-56, 2018.

Dossiê Especial: Português como Língua Adicional em contextos de minorias:

(co)construindo sentidos a partir das margens

BIZON \& DINIZ (Orgs.)

CABETE, M.A. O processo de ensino-aprendizagem do português enquanto língua de acolhimento. Dissertação (Mestrado em Língua e Cultura Portuguesa) Universidade de Lisboa, Lisboa, 2010.

CAMARGO, H.R.E.; ANUNCIAÇÃO, R. O Exame Celpe-Bras e a Naturalização de Migrantes no Brasil. (em fase de elaboração).

CANAGARAJAH, S. Translingual practice: Global Englishes and cosmopolitan relations. New York: Routledge, 2013.

CAVALCANTI, M.C. Estudos sobre educação bilíngue e escolarização em contextos de minorias linguísticas no Brasil. D.E.L.T.A., v. 15, número especial, p. 385-418, 1999.

Bi/multilinguismo, escolarização e o (re)conhecimento de contextos minoritários, minoritarizados e invisibilizados. In: MAGALHÃES, M.C; FIDALGO, S.; SHIMOURA, A. (Orgs.). A formação no contexto escolar: uma perspectiva críticocolaborativa. Campinas,SP: Mercado de Letras, 2011, p. 171-185.

CÉSAR, A.; CAVALCANTI, M.C. Do singular ao multifacetado: o conceito de língua como caleidoscópio. In: CAVALCANTI, M.C.; BORTONI-RICARDO, S.(Orgs.). Transculturalidade, linguagem e educação. Campinas,SP: Mercado de Letras, 2007, p. $45-66$.

CUCHE, D. A noção de culturas nas ciências sociais. Bauru: EDUSC, 1999.

DIAS, A. L.K.; PINTO, J.P. Ideologias linguísticas e regimes de testes de língua para migrantes no Brasil. Revista Brasileira de Linguística Aplicada, v. 17, n. 1, p. 61-81, 2017.

DINIZ, L.R.A. Mercado de línguas: a instrumentalização brasileira do português como língua estrangeira. Dissertação (Mestrado em Linguística) - Instituto de Estudos da Linguagem/Universidade Estadual de Campinas, Campinas, 2008.

FOUCAULT, M. A Ordem do Discurso. São Paulo: Loyola, 2005.

FREIRE, P. Pedagogia do oprimido. São Paulo: Paz e Terra, 2011.

GEDIEL, J.A.; CASAGRANDE, M.; KRAMER, J. Universidade e hospitalidade: uma introdução ou mais um esforço! In: GEDIEL, J.A.; GODOY, G.(Orgs.). Refúgio e hospitalidade. Curitiba: Kairós, 2016, p. 21-35.

GROSSO, M. J. Língua de acolhimento, língua de integração. Revista Horizontes de Linguística Aplicada, v. 9, n. 2, p. 61-77, 2010. 
REVISTA X, Curitiba, volume 13,n.1, p. 35-56, 2018.

Dossiê Especial: Português como Língua Adicional em contextos de minorias:

(co)construindo sentidos a partir das margens

BIZON \& DINIZ (Orgs.)

GUIMARÃES, E. Semântica do acontecimento. Campinas: Pontes, 2002.

Espaço de enunciação, cena enunciativa, designação. Fragmentum, n. 40, 2015, p. 49-68.

JORDÃO, C.M. Abordagem comunicativa, pedagogia crítica e letramento crítico: farinhas do mesmo saco. In: ROCHA, C.H.; MACIEL, R.F.(Orgs.). Língua estrangeira e formação cidadã: por entre discursos e práticas. Campinas, SP: Pontes, 2013, p. 69-90.

LOPEZ, A.P. Subsídios para o planejamento de cursos de Português como Língua de Acolhimento para imigrantes deslocados forçados no Brasil. Dissertação (Mestrado em Linguística Aplicada) - Universidade Federal de Minas Gerais, Belo Horizonte, 2016.

MAHER, T.J.M. Do casulo ao movimento: a suspensão das certezas na educação bilíngue e intercultural. In: CAVALCANTI, M.C.; BORTONI-RICARDO, S. (Orgs.). Transculturalidade, linguagem e educação. Campinas,SP: Mercado de Letras, 2007a, p. 67-94.

A educação do entorno para a interculturalidade e o plurilinguismo. In: KLEIMAN, A.B.; CAVALCANTI, M.C. (Orgs.). Linguística Aplicada - suas faces e interfaces. Campinas,SP: Mercado de Letras, 2007b, p. 255-270.

MAKONI, S.; PENNYCOOK, A. Disinventing and (re) constituting languages. Critical Inquiry in Language Studies: an international journal, v. 2, n. 3, p. 137-156, 2005.

MERTON, R. Social structure and anomie. American Sociological Review, v. 3, n. 5, p. 672-682, 1938.

NORTON, B. Identity and language learning: extending the conversation. Bristol: Multilingual Matters, 2013.

RYMES, B. Communicating beyond language: everyday encounters with diversity. New York: Routledge, Taylor \& Francis Group, 2014.

SANTOS, M.A. Por uma outra globalização: do pensamento único à consciência universal. Rio de Janeiro: Record, 2000.

SCHLATTER, M.; GARCEZ, P.M. Referenciais curriculares para o ensino de língua espanhola e de língua inglesa. Rio Grande do Sul: Secretaria de Educação do Estado, 2009.

SILVA, T.T. Identidade e diferença: a perspectiva dos estudos culturais. Petrópolis: Vozes, 2000, p. 73-102. 
REVISTA X, Curitiba, volume 13,n.1,p. 35-56, 2018.

Dossiê Especial: Português como Língua Adicional em contextos de minorias:

(co)construindo sentidos a partir das margens

BIZON \& DINIZ (Orgs.)

VIEBROCK, B. Just a change of prefix? From inter-to transcultural foreign language learning and back. In: Sloganizations in Language Education Discourse conference. 2014, p. 24. 